\title{
Is Allah die Here?
}

\author{
J.A. van Rooy \\ Dept. Ou Testament \\ Hammanskraalse Teologiese Skool/PU vir CHO \\ POTCHEFSTROOM
}

\begin{abstract}
Is Allah the Lord?

Regarding the issue whether Allah is God, much difference of opinion exists among Reformed theologians. J. H. Bavinck. John Calvin and Z. Ursinus would probahly say no in answer to the question as 10 whether Allah is God, whereas others, like Albert Kruyt and most specialists on Islam would say yes. These differences may be explained as emanaing from different approaches. The subjective-personal point of view would not recognize in Allah the God of the Bible. (jods of different fauths reflecting a distorted image of God should, however, only in a very relative and limuted way he called false gods. The exegetical poim of ' 'iew should take cognisance of Paul's statements about the (jod of Judaism in Romans 10:2 and his own experience according to 2 Timothy 1:3. These Pauline statements make it clear that the (iod of Judaism cannot historically and objectively be called an idol. Knowledge of Allah of Islam, however, is historically dependent on Judaism and (hristianity, and is therefore an extension of the knowledge Jew's and (hristians have of (jod. from a New Testament perspective Judaisn and Islam cannot be called true religions, but neither can the God they worship be called an idol in the ahsolute sense of the word.
\end{abstract}

\section{Waarom dit gaan}

Aangesien daar die afgelope tyd in die geledere van die Gereformeerde Kerke emstige meningsverskil oor hierdie saak na vore gekom het, in so 'n mate dat broeders dit nodig gevind het om ander broeders van kettery aan te kla omdat hulle nie sonder meer wil aanvaar dat Allah wat deur die Moslems gedien word, 'n afgod is nie, is dit nodig om uit die staanspoor enkele punte duidelik te stel.

In die beredenering wat ek in hierdie artikel volg, word die volgende uitgangspunte as vasstaande gestel: 
* Alle relatiwisme word verwerp asof daar nie 'n absolute waarheid sou wees nie.

* Die idee dat daar enige ander Middelaar as Jesus Christus tussen God en die mense sou wees, word verwerp.

* So ook word verwerp dat daar enige ander gesaghebbende openbaringsbron naas die Heilige Skrif, die Bybel, sou wees, en

* dat Islam of die Judaïsme 'n ware godsdiens kan wees.

\section{Meningsverskil by Gereformeerde teoloë}

Daar is by Gereformeerde teoloë, wat almal van dieselfde konfessionele standpunt as die skrywer van hierdie artikel uitgaan, meningsverskil oor die kwessie of Allah van die Islam (hierna slegs genoem Allah) dieselfde God is as die Here, die Vader van onse Here Jesus Christus. So kom daar in een versamelwerk van 'n groep behoudende Nederlandse gereformeerde teoloë, Sinat en Ardjoeno (Delleman, 1946), uiteenlopende standpunte oor die saak na vore, maar sonder dat daarvan bewustelik 'n twispunt gemaak word. J.H. Bavinck meen:

Men kan God slechts op een manier hebben, nl. op de wijze waarin Hij Zichzelf in Christus aan ons geopenbaard heeft. Ieder die Hem anders heeft, die heeft niet slechts een andere opvatting over Hem, maar die heeft wel terdege een 'anderen god' (Delleman, 1946:24, 25).

In dieselfde werk skryf dr. Albert C. Kruyt, die bekende 'apostel van die Toradjas' en sendeling van die Gereformeerde Bond, die volgende:

Want ook Mohammed kende den aan Israel geopenbaarden God ... Niet minder fel dan Mozes is Mohammed opgetrokken tegen het maken van afgodsbeelden en ook zijn volgelingen zijn doordrongen geworden van de heiligheid van God (Delleman, 1946:49, 50).

Ek is van mening dat daar in albei gesigspunte 'n element van waarheid lê, en dat die verskille teruggevoer kan word tot verskillende benaderingswyses, wat ek agtereenvolgens wil bespreek.

\section{Die subjektief-persoonlike gesigspunt}

Die eenvoudige Christen-gelowige wat aan Allah dink, dink aan hom as 'n ander god as die God wat hy ken. Immers, ' $n$ mens herken inderdaad nie meer die Vader van onse Here Jesus Christus in die beeld wat die Qur'an en die Islam van God teken nie. Allah is nie my Vader nie en ook nie die Vader van onse Here Jesus Christus nie. Ook is hy is nie die drieënige God nie. Gesien vanuit my per- 
soonlike subjektiewe belewing as Christen, is die saak redelik eenvoudig en daarmee afgehandel.

\section{J.H. Bavinck sê dan ook:}

Alleen wanneer wij den Doring-gekroonde in de oogen zien, dan staan wij voor God. Er is geen andere god (Delleman, 1946:44).

Twee gedugte teoloë wat die vraagstuk oorwegend vanuit hierdie gesigspunt benader, is Calvyn en Ursinus. In sy Institusiel (1.4.3) sê Calvyn dat Paulus leer "dat die Efesiërs sonder God was toe hulle van die ware kennis van die een God afgedwaal het ... As jy Hom verlaat, bly daar vir jou niks oor as 'n verfoeilike afgod nie". En Ursinus sê in sy Skatboek van verklarings oor die Heidelbergse Kategismus $(1657,2: 106)$, in sy verklaring van die tweede gebod, dat as God anders gedien word as wat Hy gedien wil wees, daar dan ' $n$ ander god gedien word. God word dan nie meer gedien nie, maar ' $n$ afgod van die menslike brein.

\subsection{Probleme met hierdic gesigspunt}

Hierdie gesigspunt kan alleen in 'n heel betreklike, beperkte sin aanvaar word, en wel om meer as een rede

In die eerste plek kan die subjektief-persoonlike standpunt nie aanvaar word nie omdat dit op menslike argumente eerder as op die Heilige Skrif gebou is. In punt 2 , die objektief-eksegetiese gesigspunt, word hierop vollediger ingegaan. Dit is logies om te sê dat as ek ' $n$ valse beeld van God het, die god wat in my inbeelding bestaan, nie meer die ware god is nie. ' $n$ Mens kan egter hierop met die ewe menslike argumentasie kom dat as ek ' $n$ valse beeld van God het, dit nog nie beteken dat die God wie se beeld ek verdraai het, ' $n$ afgod is nie. My valse beeid van God verander nie die identiteit van Hom wie se beeld ek verdraai nie. 'n Mens kan dan hoogstens sê dat Allah soos die Moslems hom dien, 'n afgod is, maar nie dat Allah vir wie die Moslems dien, ' $n$ afgod is nie.

'n Ewe ernstige probleem met hierdie gesigspunt is die vraag watter mens ' $n$ volmaakte beeld van God het. Ons kan dus met Calvyn en Ursinus saamstem dat wie ' $n$ valse godsbeeld het, ' $n$ afgode-dienaar is, maar slegs in ' $n$ beperkte en betreklike sin, naamlik in die sin dat ons almal aan hierdie sonde skuldig is. Vanuit hierdie gesigspunt moet ons toegee dat wanneer 'n gelowige kleuter God vir homself voorstel as 'n ontsaglike groot ou man tien myl bokant die aarde, dit afgodediens is, maar kan ons werklik in die absolute sin sê dat die God van daardie kleuter ' $n$ afgod is? En wat van die kleuter geld, geld van elke gelowige. Nie- 
mand het in hierdie bedeling ' $n$ volmaakte godsbeeld nie; ons ken maar gedeeltelik (1 Kor. 13:9).

Dit is duidelik dat Calvyn en Ursinus valse godsdiens vanuit hierdie spesifieke, subjektiewe gesigspunt beoordeel, en daarin lê die geldigheid van hulle standpunt. Daar kan dus geen probleem daarmee wees as iemand vanuit hierdie, subjektiewe gesigspunt saam met Calvyn en Ursinus beweer dat die Moslem, ondat hy ' $n$ valse godsbeeld het, ' $n$ afgodedienaar is nie. Die beeld wat hy van God in sy bewussyn het, is vals, afgodies. Dan moet 'n mens egter daarmee rekening hou dat in hierdie sin elke mens in hierdie bedeling, gelowiges ingesluit, in ' $n$ mindere of meerdere mate afgodedienaars is. Elke mens is skuldig aan die oortreding van die tweede gebod. Niemand is volmaak in hierdie opsig nie.

\section{Die wetenskaplike, objektiewe, eksegeties-historiese gesigspunt}

Dit word egter onmoontlik om hierdie subjektief-persoonlike gesigspunt absoluut te handhaaf wanneer ' $n$ mens na die Skrif self gaan. In hierdie opsig word spesifiek verwys na Paulus se uitspraak in Romeine 10:2 "dat die Jode vol ywer vir God is, maar sonder die regte insig". Dit sê Paulus van die Jode nadat hulle Christus as die Seun van God verwerp het, en daarmee ook die Drieëenheid van God. Vanuit die subjektief-persoonlike gesigspunt het die Jode 'n valse godsbeeld en is hulle God dus ' $n$ afgod. Nou kan ons aanneem dat Paulus geweet het wie God is en wat ' $n$ afgod is. As Paulus gedink het dat die God wat die Jode aanbid, objektief gesproke, ' $n$ afgod is, dan kan hy op geen manier, teen geen moontlike agtergrond en in geen enkele verband sê dat die Jode 'n ywer vir God het nie. Hy sou dan noodwendig moes sê dat hulle 'n ywer vir hulle afgod het. Dit is egter duidelik dat Paulus daardie moontlikheid nie eers oorweeg nie.

Ewe dwingend is die argument van Paulus se siening op sy eie godsdiens voor sy bekering. Hy het geen goeie woord vir sy eie godsdiens nie: sy wetsgeregtigheid is waardeloos, verwerplik (Fil. 3:7,8) - dit was inderdaad valse godsdiens. Tog kom die gedagte nie eers by hom op dat hy ' $n$ afgod gedien het nie. In 2 Timoteus 1:3 sê hy dat hy God ởò roơóvwov, "van my voorouers af" (1983: "net soos my voorouers") met 'n skoon gewete dien.

Het feit, dat in deze dienst van God door zijn bekering een geweldige ingreep was gekomen, verhindert hem niet dit uit te spreken. Want het was niet een andere God, die hij was gaan dienen, en ook had de oprechtheid en ernst aan zijn godsdienstig streven niet toen pas een aanvang genomen ..., zij het, dat hij pas door de kennis van Christus in de rechte verhouding was getreden tot de God der vaderen en die reiniging van zijn conscientie door het geloof had ontvangen (Ridderbos, 1967:177). 
Ons kan dus, objektief-eksegeties gesien, nie die standpunt handhaaf dat die Judaiste ' $n$ afgod dien nie. Hulle godsdiens is valse godsdiens, maar dit is nie diens aan ' $n$ valse god nie.

Ek hoop om verder aan aan te toon dat dieselfde vir die Islam geld. Vervolgens word nog ' $n$ enkele Gereformeerde gesaghebbende se standpunt betrek.

\section{Abraham Kuyper en ons formuliergebede}

In Januarie 1890 is 'n groot sendingkongres van die Gereformeerde Kerken in Nederland gehou. Die hoofspreker was die bekende teoloog, Abraham Kuyper en die rede wat hy daar gehou het, het vir dekades daana die sendingbeleid van die Gereformeerde Kerke in Nederland, en ook in Suid-Afrika, bepaal. Hy het by daardie geleentheid basiese beginsels aangestip oor alle belangrike aspekte van die sendingwerk: onder andere kom hy telkens terug op die onderskeid tussen heidene, Jode en Moslems.

Dit is van belang om te luister na wat hy van die Moslems sê, want ons kan dit seker nie vandag alles onderskryf nie. Kuyper besef beslis nie in watter mate die Islam mense eerder van Christus af weghou as om die weg na Hom te baan nie. Een ding is egter duidelik en dit is dat hy nie die beskouing huldig dat die Moslems 'n ander god aanbid as Christene nie. Hy sê byvoorbeeld in die rede dat die Islam die wêreldroeping het on 'n bolwerk teen die heidendom te wees (Kuyper, 1940:10). As die Moslems ' $n$ afgod aanbid en dus self heidene is, kan hulle onmoontlik 'n bolwerk teen die heidendom wees. Die hoofdwaling van die Islam is dan ook volgens hom dat hulle 'n ander, hoër openbaring teenoor die Skrif stel Hulle soort afgodery is dus nie sonde teen die eerste gebod (ander gode aanbid) nic, maar teen die tweede gebod, naamlik on die enige, ware God anders te vereer as wat Hy in sy Woord geopenbaar het. (Ek neem die eksegese van die Heidelbergse Kategismus in Vraag 96 as uitgangspunt.) Daarom sê Kuyper in dieselfde rede (Kuyper, 1940:7) dat sendelinge onder die Moslems hulle moet aansluit by die antipaganistiese strewe van die Islam, en by die ware bestanddele wat in sy belydenis van Moses en die Christus oorgebly het

Dit wil voorkom of die formuliergebed agter in die Psalmboek (p. 675) vanuit dieselfde standpunt as Kuyper 'n duidelike onderskeid tref tussen 'Jode, Mohammedane en heidene' - dit impliseer dat Jode en Moslems nie heidene is nie.

\section{Die historiese gesigspunt}

Dat ek nie wil sê dat Jode en Moslems ondanks hulle valse godsdiens ' $n$ afgod aanbid nie, beteken nie dat 'n mens dit van alle nie-Christelike godsdienste kan sê nie. Daar is baie godsdienste waarvan 'n mens kategories moet sê dat hulle gode 
afgode is. Sonder om dit te beredeneer, kan as voorbeeld genoem word die Hindoeïsme, hetsy in sy populêre vorm met sy duisende gode, hetsy in sy filosofiese vorm met sy panteistiese godsbeskouing. 'n Mens sou dit moet oorweeg of die godsbeskouing van die Jehowagetuies met hulle tweegodendom nie ook as heidens getipeer moet word nie. Sodra God nie meer as enig aanbid word nie, beland jy in ' $n$ heidense politeïsme.

Maar afgesien van die Judaisme, wat reeds bespreek is, is daar grondige historiese redes om ook van Allah vir wie die Islam aanbid, te sê dat, objektief gesproke, hy die ware God is. (Dit is des te meer waar as ' $n$ mens ongekwalifiseerd van Allah praat. Lank voordat daar so iets as Mohammed of 'n Islam was, het Arabiessprekende Jode en Christene van God as Allah gepraat. Allah is nie die eienaam vir ' $n$ bepaalde god nie, dit is die Arabiese woord vir God. Tot vandag toe is dit wat die miljoene Arabiessprekende Clıristene God noem.)

Ek beskou nie die Qur'an in enige opsig hoegenaamd as 'n openbaring van God aan Mohammed nie. Vanuit 'n Skriftuurlike standpunt gesien, kan die Qur'an niks anders as fiksie wees nie. Mohammed het geen direkte openbaring van God gehad nie, hy het by Jode en Christene van Allah gehoor, tot die oortuiging gekom dat die God van die Jode en Christene die enige ware God is, en vir die res van sy lewe al sy kragte ingespan om die diens van daardie God te bevorder. Raihana, sy sewende vrou, was 'n Jodin, die weduwee van een van die slagoffers van sy veldslag teen die Jode van Quraiza. Ook sy negende vrou, Safiyya, was die weduwee van 'n Joodse hoofman. Maryam, sy agste vrou, was 'n Egiptiese Christin-slawemeisie (Shorrosh, 1988:64, 65). By hierdie vroue, en in sy gedurige kontak met Arabiessprekende Jode en Christene, het hy baie van die Ou en Nuwe Testamente gehoor, en was hy in gedurige dialoog met Jode en Christene. Soos wat met die Jode die geval is, was hy "vol ywer vir God, maar sonder die regte insig" (Rom. 10:2).

Dis opmerklik dat hy tydens die tweede Mekkaanse periode, toe sy kontak met die Jode baie intensief was, baie dikwels die naam Al-Rahman, 'Die Barmhartige', gebruik het, ' $n$ naam wat deur die Jode in die Babiloniese Talmoed en oor die hele Arabiese wêreld gebruik is om die Hebreeuse Naam Jahwe weer te gee (Naudé, 1974:13). Dit is dus duidelik dat Mohammed opsetlik, selfs in die name wat hy vir God gebruik het, wou getuig dat hy die God van die Christene en die Jode wil aanbid. Hy het selfs aanvanklik dieselfde skroom geopenbaar wat so bekend is by die Jode om die naam van God, Jahwe of Here, uit te spreek. Net soos die Jode het hy aanvanklik hoofsaaklik die naam Rabb gebruik, wat die Arabiese vertaling van Adonai is (Naudé, 1974:15).

Daar is dus histories geen twyfel nie dat Mohammed by Jode en Christene van God die Here gehoor het. Die Christene met wie hy egter te doene gekry het, was self nie suiwer in hulle leer oor God nie. Die Arabiese woestyn was destyds, 
na die teologiese stryd by Chalcedon in 451 n. C., 'n toevlugsoord juis vir ketters wat aan die vervolging van die ortodoksie wou ontkom. Onder hulle was die Monofisiete wat die mensheid van Christus so volkome in sy godheid laat versmelt het dat daar eintlik niks daarvan oorgebly het nie. "In aansluiting hierby leer hulle dat Maria theotokos, 'die moeder van God' is" (Naudé, 1974:30). Mohammed moes dus na alle waarskynlikheid by hierdie Christene afgelei het dat hulle glo in 'n Drieèenheid wat bestaan uit die Vader, Maria en die Seun. Dit het hy verwerp. Hy het waarskynlik nooit die Skriftuurlike leer van die Drieëenheid hoor verkondig nie en hom ook nooit daarteen uitgespreek nie. Waarteen hy hom wel uitgespreek het, is die idee van 'n driegodendom waarvan hy by sommige Christene gehoor het, altans soos hy hulle verstaan het.

Anders as sommige Judaïste, het Mohammed altyd net met die grootste respek van Isa, Jesus, gepraat. Hoewel hy daarin gedwaal het dat hy Jesus se godheid ontken het, het hy meer van die Nuwe-Testamentiese openbaring oor Jesus aanvaar as wat die Jode bereid was on te aanvaar. So het hy die maagdelike geboorte van Jesus, sy sondeloosheid, sy hemelvaart en sy wederkoms in die toekoms aanvaar (Shorrosh, 1988:82-102) - alınal leerstellings wat deur die Judaisme verwerp word.

Die standpunt wat ek met hierdie betoog wil stel, is dit: Mohammed het Allah nie uitgedink nie, hy het by Christene van Hom gehoor. Hy sluit dus aan by die besondere openharing in Jesus (hristus en in die Skrif. Hy verwerp egter 'n gedeelte van daardie openbaring: liy verdraai God se beeld. In die betreklike, beperkte sin waarin Calvyn en Ursinus sê dat 'n verdraaide godsbeeld afgodediens is, is hy, soos ons almal, 'll afgodedienaar, maar in die absolute, objektiewe sin kan ons nie sê dat die God wie se beeld hy verdraai het, ' $n$ afgod is nie.

Dit is opmerklik dat onse Here Jesus in sy twisgesprek met die Jode (Joh. 8:1259) sy Joodse teenstanders "kinders van die duiwel" noem (vs. 44) - God is nie hulle Vader nie. Nogtans sê Jesus nie dat die God wat hulle vereer, ' $n$ afgod is nie - hy sê slegs dat hulle nie sy kinders is nie; hulle godsdiens is vergeefse godsdiens. Daarvan sê onse Here Jesus in Matteus 15:8,9:

Hierdie volk eer My met hulle mond. maar hulle hart is ver van My af.

Dit help niks dat hulle my probeer dien deur leerstellings van mense as gebooie van God voor te hou nie.

Hulle godsdiens is sonder meer valse godsdiens, en Calvyn en Ursinus kan dit seker tereg 'afgodediens' noem. Nogtans sê God self dat hulle in hierdie valse, vergeefse godsdiens, $H o m$ vereer ("Hierdie volk eer $M y$ met hulle mond").

Baie insiggewend in verband met hierdie gesigspunt is die geskiedenis van die ontstaan van die Samaritane wat in 2 Konings 17 weergegee word. Hier het ons 
'n klassieke voorbeeld van 'n valse, sinkretistiese godsdiens. Sewehonderd jaar later sê onse Here Jesus nog aan die Samaritaanse vrou: "Julle aanbid sonder om te weet wat julle aanbid ..." (Joh. 4:22). Daardie Samaritane was ongetwyfeld afgodedienaars. Hulle het selfs van die ware God 'n afgod gemaak, omdat hulle Hom soos een van hulle afgode behandel het. Maar wat is die uitspraak van die geinspireerde Woord van God self oor hulle godsdiens? Dit lees ons in 2 Konings 17:33, 34:

Hulle het die HERE vereer en ook hulle eie gode gedien. Hulle vrees die HERE nie en handel ook nie volgens hulle insettinge en hulle gebruike nie.

Let op dat vers 33 sê dat hulle die Here vereer, terwyl vers 34 sê dat hulle hom nie vrees nie. Die uitmuntende Duitse vertaling, Gute Nachricht, vertaal dit so:

So dienten sie gleichzeitig den Herm und ihren eigenen Göttern ...(33). Sie nehmen den Herrn nicht ernst ...(34)

Waaroor geen vertaling verskil nie, is dat in 17:33 gesê word dat hulle die Here dien. Hulle godsdiens is vals, en hulle dien God asof hy ' $n$ afgod is, maar dit is, objektief gesproke, nog die Here vir wie hulle dien. In vers 33 kom die objektiewe gesigspunt na vore ("Hulle dien die Here") en in vers 34 die subjektiewe ("Hulle dien die Here nie". Groot Nieuws: "Ze aanbidden de Heer niet zoals het moet).

Hierdie uitspraak geld ook van Moslems, wat, soos die Judaïste, Christus verwerp.

Dit mag nuttig wees om die argument met behulp van 'n beeld te verduidelik. As ' $n$ mens op ' $n$ dynserige dag langs ' $n$ huis in die veld staan, kan jy ' $n$ korrekte beeld van daardie huis vorm. Jy kan sien of dit van klip of steen gebou is, hoeveel vensters dit het, waarvan die dak gemaak is, en of die deure geverf is. Staan jy egter twee kilometer van daardie huis af, sien jy nog net ' $n$ vaal of wit kol. Jy kan vermoed dis 'n huis, maar dit kan ook 'n skuur wees, of net 'n muur. Subjektief, wat jou waarneming betref, het jy nie meer ' $n$ juiste beeld nie, maar dit waarvan $j y$ ' $n$ onjuiste beeld het, is nog steeds dieselfde huis. Jou valse beeld verander nog nie die identiteit van die huis nie: dit bly ' $n$ huis. So is dit met die godsbegrip van Jode en Moslems: hulle ken God nie; hulle staan ver van Hom af, maar hulle weet wel van Hom, en Hy van wie hulle weet sonder om Hom werklik te ken, is die ware God.

\section{Die siening van missioloë}

Daar is nouliks enige Christelike sendeling of missioloog wat onder Moslems werk, wat sal aanvaar dat hulle na die Moslems kom met die evangelie van 'n God van wie hulle niks weet nie. Oor die algemeen aanvaar bekeerde Moslems 
dat hulle, soos Paulus, dieselfde God aanbid as in die tyd voor hulle Christene was, maar dat hulle Hoin nou vir die eerste keer persoonlik, in die Bybelse sin van die woord, ken. Sendelinge en missioloë deel hierdie standpunt. Ons kan hiervoor verwys onder andere na Phil Parshall (1989:23 e.v.) in sy boek The Cross and the Crescent. Dit bring ons dan ook by die laaste gesigspunt, naamlik die missiologies-taktiese gesigspunt.

\subsection{Die missiologies-taktiese gesigspunt}

Paulus wandel, volgens Handelinge 17:23, deur die stad Atene, en sien daar 'n altaar opgedra "aan 'n onbekende god". Dit word algemeen aanvaar dat die bedoeling van die Ateners nie was om die Here, die God van die Jode, wat Hom in die Skrif aan Israel geopenbaar het, met hierdie altaar te vereer nie. Hulle het eenvoudig op 'n keer besef dat daar iemand is wat hulle nie ken nie, maar wat groot en magtig is en wat vereer moet word. Paulus sêt mmers in Romeine 1:20 en 21 dat die heidene van God weet ondat hulle sy werke duidelik kan sien. Hulle beskou hierdie God nie as die Vader van onse Here Jesus nie: hulle weet niks van die Drieëenheid nie; hulle wil God nie regtig ken nie. Hulle wete van God berus nie, soos dié van Jode en Moslems, op die openbaring van God in die Bybel nie, en dit sluit ook nie daarby aan nie Nogtans durf Paulus aan hulle sê: "Wat julle aanbid sonder on daarvan kernis te dra, verkondig ek aan julle" (Hand. 17:24).

Op grond van wat ck in punt 4 betoog het, kan 'n Christen wat die evangelie aan Moslems verkondig, dan seker met veel meer grond aan hulle sê: 'Hom wat julle aanbid sonder om Hom te ken, verkondig ek aan julle.' Die feit dat die Moslem die God wat hy aanbid, nie persoonlik ken nie en verkeerde idees oor Hom het, maak volgens hierdie benadering nog nie van die Skepper van hemel en aarde van wie hy weet, 'n afgod nie. Die Moslem se nood is nie dat hy 'n afgod aanbid nie sy nood is, soos dié van die Jood, dat hy die God wat hy aanbid, nie ken nie; daarom is hy, soos die Jood wat Clıristus verwerp, verlore.

Ons kan nie 'n Moslem na Christus toe bring nie, dit kan die Heilige Gees alleen doen. Ons roeping is egter wel om Clristus na die Moslems toe te bring - en dit kan ons beter doen as ons ook met die objektief-historiese gesigspunt rekening hou. Op hierdie wyse breek ons nie by voorbaat kommunikasie af deur vir die Moslem te sê dat hy ' $n$ ander god as ons dien nie, maar word kommunikasie wel bevestig deurdat ons aan hom die ware kemns bring oor die God wat hy dien.

Ons bely in die Nederlandse Geloofsbelydenis die volgende oor God:

Ons glo almal met die hart en bely met die mond dat daar ' $n$ enige en enkelvoudige geestelike Wese is wat ons God noem. Hy is ewig, onbegryplik, 
onsienlik, onveranderlik, oneindig, almagtig, volkome wys, regverdig, goed en die aller-oorvloedigste fontein van alles wat goed is.

Allah, ook soos die Moslems Hom aanbid, word in hierdie artikel van die NGB perfek beskryf. Daar is geen Moslem wat nie elke woord van hierdie artikel volmondig sal kan onderskryf nie.

\section{Gevolgtrekking: ketterjagtery is onnodig}

Dit mag wees dat nie alle Gereformeerde teoloë met my argumente sal saamstem nie. Dit is hulle goeie reg, en hulle mag dalk selfs geldige argumente vir hulle standpunt na vore bring - alhoewel niemand tot dusver probeer het nie. Om egter teoloë wat wel hierdie argumente onderskryf, te beskuldig dat hulle alleen hierdie standpunt kan huldig deur hulle geloof in Christus as die enigste Middelaar, in die Heilige Skrif as die enigste gesaghebbende openbaringsbron oor God, en selfs hulle geloof in die Vader van onse Here Jesus Christus as die enige ware God prys te gee, is eenvoudig onwaar. Enigeen wat hierdie artikel met die geringste mate van Christelike welwillendheid lees, al stem hy nie daarmee saam nie, sal ten minste moet insien dat die manier van argumenteer wat hierin gevolg word ' $n$ moontlike weg is om by die konklusie uit te kom dat Allah nie 'n afgod is nie. Die doel van hierdie artikel is dus nie net 'n poging om 'n wetenskaplike bydrae te lewer nie, maar ook om verdraagsaamheid onder Gereformeerde broeders te probeer bevorder oor 'n saak wat nie die wese van ons geloof raak nie.

\section{Bibliografie}

CALVYN, J. 1984 Institusie, Boek I Potchefstroom Calvyn Jubileum Boekefonds

DELLEMAN, Th, red 1946 Sinai en Ardjoeno Het Indonesische volksleven in het licht der Tien Geboden Aalten : De Graafschap

KUYPER, A. 1940. Historisch document Utrecht : Bootsma

NAUDE, J A., VAN SELMS, A \& JONKER, W D 1974 In gesprek met Islam Bloemfontein : N.G Sendinguitgewers

PARSHALL, P 1989 The Cross and the Crescent Wheaton : Tyndale House

RIDDERBOS H. N. 1967. De Pastorale Brieven. Kampen: Kok

SHORROSH, A. A 1988 Islam Revealed A Christian Arab's View of Islam Nashville Thomas Nelson

URSINUS, $Z$ 1657. Het tweede deel van het Schatboek der verklaringen over den Nederlandschen Catechismus Amsterdam Van Ravesteyn 